\title{
Ana I. Ferreyra y Luis A. Tognetti (directores). Cuestiones agrarias argentinas. La tierra como bien de producción, intercambio y factor de presión política, Buenos Aires, Imago Mundi, 2018, 160 pp.
}

\author{
Silvana Villanueva \\ Universidad Nacional del Centro de la Provincia de Buenos Aires. \\ CONICET, Argentina \\ villanuevasilvana1@gmail.com \\ Luciano Barandiarán \\ Universidad Nacional del Centro de la Provincia de Buenos Aires. \\ CONICET, Argentina \\ cleido7@yahoo.com.ar
}

El libro dirigido por Ana Inés Ferreyra y Luis Tognetti es una compilación de artículos que conforma la segunda entrega de Cuestiones agrarias argentinas. ${ }^{1}$ Los trabajos que allí se presentan se realizaron en el marco de un proyecto subsidiado por CONICET y fueron analizados por evaluadores externos antes de ser publicados. $^{2}$ Como mencionan sus directores en la presentación del libro, las diferentes investigaciones recuperan debates historiográficos vinculados con la problemática de la tierra para avanzar en sus específicas propuestas de investigación. Éstas centran el análisis en la situación rural de la provincia de Córdoba y en menor medida de Buenos Aires, desde el fin de la colonia hasta principios del siglo XX.

A pesar de que en los últimos años las investigaciones académicas en torno a la tierra y sus múltiples aristas han sido menores en referencia a la importancia que presentó su estudio desde el advenimiento de la democracia en 1983, no deja de ser un tema relevante considerando la naturaleza del país, y la importancia que el campo tuvo y tiene en la realidad económica, política y social, al igual que en los imaginarios creados en torno a su impronta en la identidad nacional. Por eso, cada capítulo del libro aborda su temática específica haciendo un recorrido por los vínculos existentes entre sociedad, Estado y tierra. En cada caso, los autores proponen un minucioso análisis no sólo de los aportes bibliográficos sobre el tema abordado sino también sobre las fuentes consultadas para poder avanzar en los problemas e hipótesis planteados.

Si pensamos en los temas que aborda el libro podemos distinguir tres ejes de análisis: la circulación de la tierra (Ferreyra); la relación sociedad-recursos hídricos (Garnero) y el proceso de colonización (Tognetti, Massei y Blanco). Por ende, a continuación los desarrollaremos atendiendo a ese criterio.

En el primer capítulo, "La circulación de la propiedad rural en Córdoba, (1800-1855). ¿Un mercado incipiente?”, Ana Inés Ferreyra recupera el debate sobre la constitución del mercado de tierras en Córdoba con el fin de aproximarse a sus orígenes, analizando el concepto de mercado de tierras y las categorías históricas a él asociado. A partir de la comparación con el caso más trabajado de Buenos Aires, avanza en la hipótesis de la existencia de un incipiente mercado de tierras ya para inicios del siglo XIX. Para entender sus características específicas, analiza el movimiento inmobiliario de tierras rurales cordobesas en la primera mitad del siglo XIX en la zona cercana a la ciudad de Córdoba y al valle de Punilla. Se adentra en el análisis de las operaciones de 
compra-venta registradas en las actas notariales, mensuras y expedientes judiciales, iluminando los problemas que presentan estas fuentes. Observa que, en el caso de Córdoba, la mayoría de las transacciones se daban en el ámbito familiar, y que existía un precio aproximado en las transacciones así como canales de información para acceder a él. En el período abordado, el escaso movimiento registrado en transacciones con tierras públicas se debió a que se encontraban en espacios considerados poco seguros; por ende, los productores agropecuarios optaron por intensificar la explotación de las tierras ya ocupadas. En síntesis, Ferreyra observa un movimiento de circulación de la propiedad de la tierra mayor que el supuesto; y una marcada diferencia entre los precios de las tierras públicas y las privadas, diferencia vinculada a su ubicación y calidad, por lo cual ya existiría un mercado de tierras para fines del siglo XVIII.

En relación con la segunda temática mencionada, Gabriel Garnero desarrolla en el capítulo "El rol del Estado en la relación sociedad / río: el agua y la tierra de la cuenca del río de Los Sauces, Traslasierra (1850-1900)" un particular análisis sobre el vínculo del Estado, la sociedad y el agua en esa región de Córdoba. Su investigación tiene dos objetivos: dilucidar la influencia que tuvo el Estado provincial en las transformaciones del vínculo entre el sistema hídrico del río de Los Sauces y la sociedad serrana, y cómo esta injerencia sobre la cuenca implicaba un progresivo control sobre dinámicas sociales y económicas. Y descubrir de qué forma los cambios que afectaron al país y en especial el espacio que estudia impulsaron los proyectos modernizadores del sistema de irrigación en el noroeste cordobés. Tras explicar el uso dado a los conceptos cuenca hidrográfica y sistema de irrigación, estudia las características específicas del caso bajo estudio en el período previo. Ello le permite explicar cómo se fue estableciendo el vínculo de la sociedad con el río, principalmente los usos que ésta hacía del agua. Esta situación fue evidenciando, a su entender, la carencia de legislación que reglamentara el uso del agua. En 1877 se elaboró el primer reglamento al respecto, la primera de una sucesión de acciones llevadas adelante por el Estado provincial para modernizar y gestionar el sistema de irrigación. En su análisis, el autor recupera distintos momentos en los cuales se legisló sobre el tema, enfatizando las novedades introducidas por el Código Civil de 1871, que determinó que los cursos de agua eran propiedad del Estado y que era tarea de las provincias reglamentar su uso y aprovechamiento. Por otra parte, en el Código Rural de la provincia sancionado en 1885 se reglamentó el régimen de peticiones de riego. La consolidación del Estado provincial y la progresiva predominancia del modelo productivo agroexportador fueron transformando la realidad provincial y creando nuevas necesidades, lo que llevó a una mayor acción gubernamental en el desarrollo y modernización de los sistemas de irrigación. Estos avances del Estado provincial en el control del reparto de agua se encontraron con obstáculos como la persistencia de prácticas tradicionales, y la carencia de personal técnico y administrativo.

Finalmente, la tercera temática que se aborda es la colonización de la tierra y nuclea los trabajos de los tres autores ya mencionados.

En el caso de Córdoba, el proceso es abordado inicialmente por Luis Tognetti en su artículo "La colonización agraria como negocio inmobiliario a fines del XIX. Una revisión de sus factores explicativos”. A partir de la revisión de la literatura sobre el proceso de colonización desarrollado en Córdoba en la segunda mitad del siglo XIX, pone en consideración si las leyes de promoción de colonias dictadas por el Estado, la ampliación de la red ferroviaria y la difusión de la misma actividad en Santa Fe dinamizaron dicho proceso. El autor vuelve a problematizar esos postulados en función de distintos interrogantes. Para visualizar su validez y su alcance, centrará su análisis en el territorio que abarca los antiguos departamentos de Unión y Marcos Juárez, en el sureste provincial, en el período en el que se manifiesta una mayor intensidad del proceso de colonización. Para ello toma en cuenta tres aspectos: mayor presencia de colonias fundadas; diferencias de establecimientos entre uno y otro departamento; y los ramales construidos en esos años que atravesaron ambos departamentos. Las fuentes que utiliza son los informes de los inspectores de colonización de las campañas; para constatar la información allí brindada, recurrió a expedientes de colonias pertenecientes a estos departamentos. En líneas generales, el estudio detallado de ambos departamentos le permite relativizar la incidencia de aquellos factores explicativos, complejizando el alcance de esas variables. 
El otro trabajo que aborda el caso cordobés es el artículo de Alejandra Massei titulado "Colonización, producción y mercado de tierras en la colonia Deán Funes (1894-1944). Estudio de casos”. A partir del estudio de esta colonia, la autora se propone indagar sobre los principales efectos que produjo el proceso de colonización y producción sobre el mercado de tierras local, desde el momento de su fundación hasta la cuarta década del siglo XX. Las fuentes que utiliza son protocolos notariales, catastrales y sobre todo archivos privados. Al trabajar en torno a un estudio de caso, su investigación brinda un enriquecedor análisis de las características asumidas por el proceso de colonización que se dio en ese territorio. Así, remontándose a los orígenes de la colonia impulsada en 1894 por Benjamín Sastre, recorre el cambio producido tras la llegada de inmigrantes; la participación de intermediarios en la venta de terrenos; la evolución de los precios entre un período y otro; las características de las inversiones de capital; la puesta en producción de la tierra y la construcción de infraestructura, entre otros elementos que permiten un acercamiento a los vaivenes asumidos por la colonización. A través del seguimiento de dos familias de inmigrantes, Ariaudo y Jaureguialzo, observa cómo cada familia adquirió tierras, el origen del capital que poseían para realizar las transacciones, la actividad a la cual destinaron esas tierras, las inversiones que allí realizaron en forestación, infraestructura, etc. Para concluir, afirma que el proceso de colonización del sudeste de la provincia de Córdoba se dio a fines del siglo XIX, momento en cual las tierras que no se encontraban en producción entraron al mercado. Además, reconoce dos etapas en las cuales la tierra jugó roles diferentes; en un primer momento, a partir de 1864 y hasta la década de 1890, la compra-venta de las tierras estuvo en manos de inversores de diversos orígenes que la utilizaron como capital líquido con un fin especulativo, etapa en la que se sitúan los orígenes de la colonia Deán Funes. Y luego, una etapa productiva con el fraccionamiento de las tierras, la llegada de los inmigrantes, la ocupación y la puesta en producción. La llegada del ferrocarril introdujo mejoras que impactaron en la evolución de los precios de la tierra.

Finalmente, el caso bonaerense es abordado por Mónica Blanco en su artículo sobre el partido de Necochea, titulado "La colonización agraria en la provincia de Buenos Aires durante el siglo XX. Un análisis de caso". A pesar de ser otro caso provincial, presenta numerosas vinculaciones con los trabajos anteriores en tanto se refiere al rol del Estado, la incidencia de las fuentes o las formas de pensar los problemas planteados. Su reflexión se sitúa en el marco de las demandas por cambios en la estructura agraria que se perciben a lo largo del siglo XX en América Latina. El objetivo de la autora es indagar sobre el rol que tuvo el Estado en el diseño e implementación de la política de colonización en el espacio bonaerense. Para ello utiliza como estudios de caso las colonias constituidas en el partido de Necochea, ubicado en el sudeste bonaerense, donde el Estado provincial impulsó entre 1929 y 1969 la fundación de siete colonias, de las que la autora destaca Rincón del Quequén, Calangueyu, Presidente Rivadavia y El Carmen. Sostiene que las propiedades sobre las que se fundaron estas colonias fueron adquiridas por el gobierno bonaerense mediante compra directa, y las experiencias de colonización tuvieron diversas improntas y desafíos. La documentación consultada es limitada ya que sólo existen relevamientos del Ministerio de Asuntos Agrarios y algunas memorias de entidades bancarias participantes. Por ello, lo que pretende este trabajo es una aproximación parcial al proceso de colonización que pueda dar cuenta de la importancia que tuvo en este partido, así como las características que asumieron las colonias creadas en ese territorio.

Para su análisis, remite a la legislación agraria elaborada en la primera mitad del siglo XX, destacando la ley nacional de colonización 12.636 de los años cuarenta, y fundamentalmente la mayor injerencia del Estado en la elaboración de políticas agrarias a partir del advenimiento del peronismo. Entre 1937 y 1972 se crearon 60 colonias en la provincia de Buenos Aires, colonización que fue acompañada por entidades bancarias nacionales que contribuyeron con préstamos e inversión de capital. Tras describir la acción estatal y la acción de estas instituciones, la autora se introduce en el estudio de caso seleccionado. Luego de una descripción del espacio seleccionado, se adentra en el origen de cada una de las colonias, los mecanismos por los cuales se fundaron y en quiénes eran sus destinatarios y qué tipo de actividad se desarrollaban en ellas. Esta primera aproximación da cuenta de la importancia que el proceso colonizador tuvo en el partido seleccionado, así 
como las distintas instituciones que intervinieron, los mecanismos que caracterizaron dicha colonización, los territorios expropiados, los precios en los que estaban valuados los territorios, las actividades productivas que debían desarrollarse en ellas y los destinatarios de esos lotes. Asimismo, explica las limitaciones del proceso colonizador.

En síntesis, observamos que, tal como se lo proponen los autores, los trabajos mencionados son de gran interés para avanzar en el conocimiento de los usos de la tierra en distintos períodos, el avance del Estado sobre la organización de ese espacio y el vínculo entre la tierra y distintos sectores sociales. En este sentido, es loable rescatar el recorrido bibliográfico que hacen los autores, la puesta en cuestión o al menos el ejercicio de repreguntarse sobre algunas consideraciones historiográficas, y sobre los distintos elementos que caracterizaron el proceso de colonización de la tierra en diferentes momentos en las provincias de Córdoba y Buenos Aires. Por otra parte, cada uno de los capítulos está acompañado de cuadros, gráficos ilustraciones, mapas, que permiten acercarnos a las fuentes trabajadas y a los datos que utilizaron en la construcción de su investigación.

Se trata, en pocas palabras, de un libro que abre nuevas posibilidades de indagación ya que posibilita, a través de las distintas variables tomadas, avanzar en el análisis de casos que permitan concluir las hipótesis aquí abordadas en lugares como Marcos Juárez, Unión, Deán Funes o Necochea.

\section{Notas}

1 La primera entrega de este trabajo, bajo la dirección de Ana Inés Ferreyra, fue publicada en 2010 por la editorial BrujasCEH Carlos S. A. Segreti, Córdoba.

2 La referencia es al proyecto La tierra como bien producción y capital simbólico, como bien de cambio o activo líquido y como factor de presión politica. De la colonia al siglo XX, que, como ya se mencionó, fue subsidiado por el Consejo Nacional de Investigaciones Científicas y Técnicas. Los evaluadores externos del trabajo fueron Julio Djenderedjian, Juan Manuel Cerdá y Adrián Zarrilli. 